\title{
Framing young people's educational transitions: the role of local and contemporary economic contexts.
}

\begin{abstract}
Despite rates of participation in post-compulsory full-time education reaching approximately $84 \%$ in Wales, social class inequalities continue to shape young people's transitions from compulsory to post-compulsory education. The paper draws upon data from a project which explored how young people's educational decisions and transitions in Wales, UK are influenced by both national economic landscapes, the popular narratives framing them, and the structure of local employment opportunities. The analyses revealed that young people from similar social class backgrounds, but living in different localities, make very different sorts of transition from compulsory to postcompulsory education; in essence they are either 'pushed' or they 'jump' into post-16 education. The paper aims overall to contribute both empirically and theoretically to understandings of the complexity of educational decision making, revealing how class and location intersect to frame decision making processes, in so doing producing and reproducing educational inequalities.
\end{abstract}

Key words: transitions, locality, education, youth 


\section{Introduction}

Sociologists from the UK as well as internationally have long established that young people's post-school choices, transitions and employment prospects depend not only on their qualifications, age, gender, social class and personal attributes, but on where they live and the availability of employment and education opportunities in local settings (Roberts 1984; Coffield et al. 1986; Furlong and Cartmel 1995; McDowell 2003; Furlong and Kelly, 2005; MacLeod and Yates 2006). In illuminating the significance of local contexts in young people's lives, the 'youth transitions' literature has clearly documented that young people from different social and economic backgrounds and living in different places follow varied and hierarchically differentiated pathways through post-16 education and beyond (Bates and Riseborough 1993; Ball et al. 2000; McDowell 2003). Those from the least socially advantaged homes are far less likely to pursue the most prestigious routes through post-16 education (namely studying for GCE AS/A-levels ${ }^{1}$ ) and to progress on to higher education (HE) than their more socially advantaged counter-parts (Ball et al. 2000; Pring et al. 2009).

In explaining these inequitable patterns of transition through post-16 education, contrasting theories of either cultural reproduction or rational choice have been utilised by researchers. Cultural reproduction theories tend to emphasise the 'powerful reproductive forces' (Parker, 2000: 127) that underpin young people's access to and participation in education. In this vein, many researchers have applied Bourdieu's (1977) concept 'habitus' to explain how early childhood socialisation, as well as cultural and economic capitals on which individuals draw, inform their orientations and dispositions towards particular educational pathways and destinations (Reay et al. 2001; Ball et al. 2002). This research has been invaluable in explaining how inequitable patterns of participation in particular prestigious educational pathways such as HE become reproduced through the way in which cultural, social and economic contexts inform and to some extent 'shape' young people's educational choices and transitions. In contrast, sociologists committed to rational choice (or action) theory (RCT) tend to argue that decisions and choices are based on considered judgement and calculative cost-reward analyses in relation to goals and preferences (Boudon 1974; Goldthorpe 1996). As such, particular educational pathways are not pursued where the costs (either financial or cultural) are perceived to outweigh the benefits (Goldthorpe 1996). 
Others have attempted to employ a mixture of these frameworks to explain class differences in educational decisions and transitions (Gambetta 1987; Rees et al. 1997; Glaesser and Cooper 2013). Gambetta (1987) for example, has illuminated the ways in which individual's make choices according to preferences and intentions, within opportunity structures, the boundaries of which are defined by external forces such as economic and social constraints. As such, educational transitions are informed by processes which both 'push' young people towards particular pathways, as well as their preferences and intentions which lead them to 'jump' towards certain destinations; both causality and intentionality are at play. Gambetta's insights have been hugely valuable in contributing to understandings of youth transitions and in bridging contrasting social reproduction and rational choice explanations.

Following Gambetta (1987) this paper aims to eschew unitary (dualistic) theoretical explanations of youth transition. It does so by exploring how young people's decisions regarding participation in post-16 education and beyond are framed (i.e., often simultaneously facilitated and constrained) by the opportunities for employment in local contexts as well as the constraints that characterise the broader national economic landscape in which young people reside. The data illuminate both the intentionality and causality within educational decisions, illustrating how individuals' educational decisions are informed by what they can do, what they want to do and conditions which shape preferences and intentions. Centring the voices of young people in two localities in Wales we will see how choices are made within a framework of opportunity defined by the scope of actually available alternatives (Gorard and Rees 2002) which are defined by their social as well as spatial location.

\section{Understanding broader contexts- Why do young people continue to post-16 education?}

In Wales the numbers of young people continuing into post-compulsory education has grown dramatically over the last 10 years. Now the majority of young people aged 16-18 living in Wales remain in some form of post-16 education (84\% in 2013) (CareersWales 2015). This has resulted in part from the expansion of courses available for post-16 learners, including an expansion of vocational qualifications such as $\mathrm{BTECs}^{2}, \mathrm{NVQs}^{3}$ and diplomas at level 2 in Wales ${ }^{4}$. It is also the effect of the expansion of HE courses, at different levels, (including HND/Cs and Foundation Degrees), delivered in both the further education (FE) and HE sector across the UK (Pring et al. 2009). This itself is expression of the 'widening participation' agendas which have dominated government HE policy discourse in England 
and Wales since the early 1990s. The expansion of HE has, however, had considerable consequences; not least intensifying competition for a limited supply of 'graduate' jobs (Mayhew and Keep 2004; Brown 2003) and fuelling a situation in which increasing numbers of people acquire jobs for which they are over-qualified (Dolton and Vignoles 2000). This, consequently, has cemented demand for higher education qualifications as young people feel ever more pressured to embark on a higher education in order to compete successfully in the labour market (Mayhew and Keep 2004; Brown 2003).

The young people in this study were then, moving from compulsory to post-compulsory education and anticipating their transitions beyond it at a time when access to post-16 education and HE in Wales, as elsewhere in the UK, had expanded greatly through the proliferation of opportunities to study at different levels and in different forms of FE and HE. Yet it was also a period in which employment opportunities for school leavers were scarce, and competition in national labour markets substantial, and in which the attainment of further and higher levels of qualifications were no longer guarantee of economic success (Brown, 2003).These socio-economic and educational conditions, which are experienced by young people across Wales, form the backdrop to our exploration of how opportunity structures in two distinct local contexts in Wales, bore upon young people's educational decisions and transitions.

\section{What about the local? The significance of local opportunities for educational transitions}

Currently, there exist two somewhat contradictory explanations for the relationship between local employment opportunities and participation in education. One explanation suggests that that abundant opportunities compel young people to remain in education because they perceive the labour market benefits of gaining extra qualifications in terms of developing their human capital (McDowell, 2003; Ashton et al. 1990). By contrast, others have explained regional variations in participation in post-16 education by drawing upon the idea of a 'discouraged worker' effect (Raffe and Willms 1986; Garner et al. 1988; Roberts, 1995; Biggart and Furlong 1996). Here, research has suggested that scarce local employment opportunities compel young people to remain in post-compulsory education in order to avoid unemployment (Garner et al, 1988; Biggart and Furlong, 1996).

While both explanations are valuable for understanding relationships between local employment opportunities and young people's educational transitions, neither alone is 
adequate as we shall see below. Moreover, these rational conceptualisations of young people's transitions, which assume that young people weigh up the relative costs and benefit of leaving education/entering the labour market, need to be set within the context of young people's social, cultural and personal circumstances. As such, the analysis which follows considers how post-school pathways into further education are connected to local industrial histories and structures of opportunity, whilst acknowledging the social and personal circumstances of young people. The following analyses therefore explore, in some detail, how local opportunities as well as contemporary economic landscapes configure particular opportunities and constraints, which together dominate young people's understandings about the relationship between education and employment and frame their educational decision making.

The aims of the paper are therefore twofold; one is to contribute theoretically to our understanding of the nature of youth transitions, in particular, to consider the extent to which educational decisions can be explained by theories of culture reproduction, rational choice or both. To this end, the paper considers how the nuances and specificities of localities define the scope of young people's objective 'opportunity structures' (Rees et al. 1997) and frame their post-school transitions. Secondly, the paper aims to move beyond using 'locality' as a proxy for social class. Many researchers have insightfully highlighted the significance of local contexts in young people's lives and their educational transitions but have used 'locality' reductively as a proxy measure for social class (Coffield et al. 1986; MacDonald et al 2005). While importantly illuminating the ways in which more or less working-class or more or less middle-class localities frame educational transitions, this research has, however, provided insufficient insight into the ways in which similar 'working-class' localities might yield variations in the distinct nature of young people's transitions in these contexts. The paper, therefore, illustrates how the nuances and specificities of each distinctive 'workingclass' locality in Wales, at a time of a global contraction of employment opportunities for the young, frame young people's decisions relating to their post-16 transitions . In doing so, a deeper and more nuanced understanding of how 'agentic' decisions which lead young people to stay in post-16 education are framed by both local contexts and historically specific economic events is provided.

\section{The study}




\section{The two localities.}

The localities of the research were purposefully selected in a way that would highlight their distinguishing features whilst holding constant some common characteristics ${ }^{5}$. This enabled a comparison of the ways in which local opportunity structures come to bear upon young people's decisions about staying on in post-16 education. Thus we feature two distinct deindustrialised localities in South Wales; both Newport and the Rhondda Valleys are often represented in popular imagination as 'typically' working class localities. These localities are less than 30 miles apart and both have experienced chronic and long-term unemployment levels which today continue to exceed the national average as a result of deindustrialisation which swept away the industries (essentially coal and steel) which once dominated in the Rhondda and Newport respectively. ${ }^{6}$

Yet these localities have followed different trajectories in reaching their present day social and economic landscapes. Today, they exhibit distinct social landscapes and senses of national identity and the structure of opportunities faced by young people living in these localities is very different. Despite being badly hit by the recent global economic 'down-turn' and having suffered from the effects of de-industrialisation which swept away much of its once prosperous steel industry, Newport experienced a period of economic optimism during the middle of the $20^{\text {th }}$ Century in a way that the Rhondda Valleys had not. Today, Newport's economic base is becoming increasingly diverse, its expanding service sector and proximity and extensive transport networks to other cities provides it with relatively greater scope for opportunities in comparison with overwhelmingly white, working-class, geographically isolated Rhondda. The Rhondda's slumped economic landscape is more entrenched than Newport's due to the demise of the coal mines and its physical geography which has prevented extensive economic investment. Today, it presents little in the way of employment opportunities, especially for school leavers.

Thus, whilst these two Welsh localities could be described as similarly working-class, sharing industrial heritages associated with manual labour and experiencing similarly high levels of present day unemployment, they are characterised by local nuances, which as we shall see, have crucial importance for the decision making processes underpinning the transitions of these young people. The paper therefore highlights the importance of moving beyond an 
analytic focus (only) on social class, and of foregrounding local distinctions within similarly working-class localities.

\section{The young people in the study}

How, then, have these distinct localities framed the educational decisions that young people make regarding staying on in post-16 education? In order to address this question, qualitative, semi-structured interviews were conducted with 57 young people, all aged 16-18, who were currently engaged in post-16 education. Just over half (31) lived in the Rhondda Valley and attended Llanon Community School ${ }^{7}$, while just under half (26) lived in Newport and attended Clayton High School ${ }^{8}$. Each individual interview lasted between approximately 3545 minutes. Interviews were conducted between September 2010 and May 2011.

Of the 31 students from the Rhondda, only six could be described as being from 'middleclass' homes, having parents with professional or managerial occupations. Four of these had at least one parent with a higher education, of which, two had a parent who had experienced $\mathrm{HE}$ as a mature student. Young people from the Rhondda were all white, born in Wales and spoke English as their first language. Similarly, a minority of young people from Newport had parents with professional or managerial jobs (four students) and of these only one had parents with experience of HE and another with a parent with experience of HE as a mature student. Students from Newport were more ethnically diverse than those from the Rhondda; eight students were from ethnic minority backgrounds or mixed heritage backgrounds, seven of these speaking additional languages to English; usually Bengali. The differences in the schools' ethnic make-up reflected those of Newport and the Rhondda at large.

Located within their schools' $6^{\text {th }}$ forms, all of these young people were studying for varying types and numbers of qualifications ranging from GCE AS/A-levels to vocational qualification (such as BTECs). The majority, however, were pursing GCE AS and A-levels. Half of the students from Clayton High School and the majority of students at Llanon Community School had GCSE attainment levels which exceeded the level 2 threshold of at least $5 \mathrm{~A}^{*}$-C grades, including Maths and English or Welsh ${ }^{9}$. A substantial minority of young people had not reached this level 2 threshold and had attainment levels significantly below it. Thus, these young people were not uniformly the academic high flyers that have traditionally 
occupied the school $6^{\text {th }}$ forms of Wales and England, and while the majority wanted to make the transition on to HE, there were a significant majority who didn't expect this destination upon leaving the $6^{\text {th }}$ form. These young people, at the time of the research, were in 'transition' and it is their decision making processes which underpin this transition that this paper hopes to capture.

\section{Why stay-on? Educational transitions in a 'cold' economic climate in Wales.}

At the time the interviews were conducted (September 2010 to May 2011) Wales, like the rest of the UK, was experiencing a 'global financial crisis' (Shah, 2010). Popular commentaries surrounding the economic 'down-turn' pervaded both media and political spheres discursively constructing a 'crisis' in the economy; the labour market was decidedly 'cold,' characterised by congestion and steep competition for limited jobs. Austerity beckoned, particularly for those already impoverished and least well off. These economic conditions (along with their discursive representations) patently had significance for how young people, in both locations, explained and rationalised their decisions to remain in post-compulsory education. In both the Rhondda and Newport students alluded to the heightened importance of educational qualifications acquired through post-16 and higher education given the shrunken and competitive conditions of the contemporary labour market. In both locations, perceptibly limited job opportunities encouraged them to stay in post-16 education, as illustrated in Callum and Mark's reflection on their decisions to continue on to $6^{\text {th }}$ form:

I think it's (the economic 'recession') actually encouraged me to stay in school for longer because maybe if I stay in school for longer the economy might change, there might be more jobs when I'm finished. So yeah I think it's actually better to stay in school right now and try and get a part time job cos after that I think you'd be sorted for a few years (Callum, Rhondda).

Res: Imagine that you hadn't stayed-on in $6^{\text {th }}$ form, what do you think you might be doing now?

M. Um probably nothing, (laughs), I'd hopefully get a job, well I have got a job but if I wasn't in school it would just be a job but because of everything that's going on it would probably be a rubbish job, but yeah. (Mark, Newport) 
Here, features of the contemporary labour market, with surrounding narratives of 'crisis,' labour market 'competition' and job scarcity, bear heavily upon these young people's educational decisions and transitions, discouraging entry to employment and encouraging continuation in FE and HE. Entering post-16 education and progression to $\mathrm{HE}$ was rationalised, not so much in terms of a desire to invest in human capital, but as means of avoiding unemployment. As such, they lend weight to Gambetta's (1987) assertion that choices are made between a limited set of alternatives, the boundaries of which have been defined by external forces.

Res. Do you think it's better to stay-on in education at the age of 16 than to leave straight away?

B. Yeah definitely well cos you get a better job, better career, more money and I think it's not really, you got all the credit crunch and things now and I wouldn't want to go out and work now cos I tried to do part-time work and I can't get a job. (Bethan, Rhondda)

P. Well at the moment with the recession and stuff and the cutbacks it's really hard to find a job, and even earning enough money, so I thought well if you go to university there is more chance of you getting qualifications and getting into different jobs that you might want to do in the future. (Parveen, Newport)

On the surface, Bethan and Parveen offer support for the notion of a 'discouraged worker' effect (Raffe and Willms 1989); i.e, staying in post-16 education is means of avoiding (or delaying) entry to a labour market which has severely limited opportunities. However, the notion of a 'discouraged worker' does not do justice to the complexity of either their perspectives or transitions. Bethan and Parveen like most other young people in the study appeared at one to emphasise the value of remaining in school in order to avoid unemployment, while also alluding to the human capital narrative, emphasising the importance of higher levels of qualifications for gaining better chances of employment. This combination of different intents is further illustrated in Alexandra's reflection on why she decided to stay on in school $6^{\text {th }}$ form:

I wanted an education and actually thought I need this to be ahead of other people to get a job, it's the same with uni in a way. I wanna go because...I can go into the police straight away as soon as I'm 18 but I'll have a bigger chance of getting in if I have a degree, and say if the police fails I'll have a degree, because if I left school and went to 
the police and didn't like it, I wouldn't have that to get me into another job so I think a degree you know makes you stand out from the others but there are so many people doing them it's going to be hard, you've just gotta have the best grades now (Alexandra, Newport)

The wider economic context with its surrounding popular commentaries of 'economic recession' and 'crisis' reinforce a more pervasive discourse dominating official 'widening participation' texts. This discourse postulates a linear relationship between attaining higher levels of educational qualifications and securing well-paid employment on the part of the individual. In both locations, young people's explanations and qualifications for staying on in post-16 education were steeped in such human capital theory, the dominant discourse in which higher levels of qualifications, especially those gained through higher education are deemed to provide access to well-paid employment within a highly competitive and congested labour market:

The current conditions in Britain I'd say it's better to stay-on because even in, at A-level, if you go into employment with A-levels with people who have got a degree there's no point, you've already lost, so get as much as you can, work for it like. (Steven, Newport) ... um like if I go to uni now there will be more debt and if I go to uni I'll have no money so I'm going to have to look for a better job to um fund university after I go. But then the job, the people with better degrees there is more competition all the way down the ladder but there is more people looking for jobs now cos there is less jobs cos of cut backs and stuff. (Craig, Rhondda)

Res. So why did you decide to stay-on in $6^{\text {th }}$ form?

J. Cos I've always, well you know like the best way to earn the highest money is to get a degree, so I further my education as much as possibly because then it opens up all my opportunities. (Jonathan, Newport)

These quotes clearly illustrate the way in which young people viewed higher education as a means of offering them 'positional advantage' (Brown 2003) when employment opportunities are scarce and competition for jobs fierce. Their 'articulated rationalities' for staying in post16 education are, at least in part, economic; staying in education provides a means of developing the human capital necessary to achieve competitive success in the labour market. 
They are making choices according to their preferences and intentions, yet do so within the scope of finite opportunities (Gambetta, 1987):

I think it's, because like it's so much more difficult, so much harder to get a job now so like the more qualifications you get through school it puts you on a better level to somebody that didn't stay-on and get their A-levels and things. (Ruth Rhondda)

I think it's the best option [referring to going to university], um it's easier to get employed, far easier to get employed after going to university than trying to look for an apprenticeship if you leave at 16 , obviously you're just more qualified. (Lewis, Rhondda)

A narrative, emphasising heightened competition and congestion within the wider labour market, dominated popular commentaries during the time these young people were transiting from compulsory to post-compulsory education. It was therefore unsurprising that these narratives were frequently reproduced in young people's explanations for staying in post-16 education and entering HE. In both locations, the decision to stay in post-16 education was as much about avoiding difficult employment contexts as acquiring human capital for successful competition within competitive labour markets. However, neither explanation either alone or together is sufficient to fully understand how young people make decisions about remaining in post-16 education. For this we need to consider how local contexts, and the employment opportunities available for young people within them, also frame their decisions.

\section{Transitions in local contexts- do local opportunities matter?}

In both the Rhondda and Newport, young people's decision to remain in post-16 education were underpinned, in part, by both a human capital discourse and an element of a 'discouraged worker effect'. Notwithstanding, there were also subtle distinctions in the decision making processes of these young people from either location.

To emphasise, both the Rhondda Valley and Newport have suffered badly, though unevenly, from industrial change and decline. The scope of employment opportunities for school leavers in the former is severely limited owing to the geographical structure of the Valley and the relatively under-developed transport networks to the Northerly parts of the Rhondda Valley. Reaching employment opportunities in nearby locations is difficult and time consuming, particularly for young people without private transport. By contrast, Newport has a more prosperous economic context and its relative proximity to other cities in South Wales makes 
it relatively more accessible to employment opportunities. These differences were reflected in striking variations between young people living in each location in the way they described the scope of employment opportunities in their locality. The majority of young people from the Rhondda viewed their locality as a place with few employment opportunities. When asked if they felt there were enough jobs locally, Lewis, Fay and Bethan replied:

No, there are very few jobs round here I think, um, there's not a lot which happens here to create jobs, the majority or jobs around here that are now being created are like charity, well not charity but Communities First ${ }^{10}$ jobs and things like that, which is quite insulting to the local area (laughs). I mean there is a lot of councillors and things like that but um the majority of people who can take those jobs come from elsewhere anyway. (Lewis, Rhondda)

No, definitely not, no. Well like obviously the mines were the biggest employer, that's all closed down so like a lot of people have left, but there's still quite a lot of people here who have got like no employment at all. (Fay, Rhondda)

No, I don't think there is. They've closed all the factories, there used to be, on the way in home from school on the main road there used to be all factories but there's not any more so I think all, most, everybody I know travels away to work, there's just supermarkets and things. (Bethan, Rhondda)

Indeed, young people's interpretations of the lack of employment opportunities were often made through reference to their own or family members' difficulties in securing employment within the Rhondda. For example, Fay reflected on her sister's experience of having to travel outside of the Rhondda in order to secure employment;

When I worked with my sister the commuting is so tiring and I think if you want a good job then you are going to have to commute quite a lot. It wouldn't bother me living here but if there was more around here that, if you know what I mean. (Fay, Rhondda).

Similarly, Robert recalled his own difficulties in securing part-time employment locally, explaining this in terms of the relatively large financial cost of travel in relation to the financial benefits of employment:

I've had one look and there was just no jobs and stuff and I, the pay they offer for 16 and 17 year olds I wouldn't get out of bed for that! It's like $£ 3$ an hour and stuff, like you 
gotta work an hour to get bus fair and stuff like that, there's not point working for it (Robert, Rhondda).

While the majority of young people from the Rhondda viewed it as a place with limited employment opportunities, by contrast, only a minority of those from Newport felt their environment to be characterised by scarce employment opportunities. Thus we have to move beyond an analytic approach which synonymises locality with social class to be able to see that whilst located in similarly 'working-class' localities, young people's employment opportunities and interpretations of them are distinct, and these distinctions have clear significance for the nature of their transitions. Young people in Newport were far more likely to reflect on the availability of employment opportunities locally than those from the Rhondda. For example, in Pratik's view, getting a job was all a matter of individual motivation, opportunity and choice:

Yeah you just got to look in the right places to be honest like some people they just can't get a job but it's just, just I reckon it's cos they're not looking hard enough...like the Lloyds TSB where I work they employ so many people there as well they've got like a staff of about a thousand, two thousand staff members and they employ temporary for December and then it could go on so it really depends where you look but I reckon if I quit my job I think I could get another job like within two weeks you just gotta look at the right places (Pratik, Newport).

In contrast, Newport's young people were also more likely to suggest that Newport, though badly hit by the recent economic recession, was a place with employment opportunities. For example, Alistair commented:

There were [jobs] but obviously now with the recession now everyone is getting chopped off and made redundant, it's getting harder and harder but I don't know I can't really say, I only had one job, I went for one job and I got it so I haven't really thought about it (Alistair, Newport)

These spatial differences in the structure of opportunities in local contexts and young people's interpretations of them were reflected in subtle differences in the nature of their transitions from school to $6^{\text {th }}$ form. For young people from the Rhondda, especially the academically successful, staying in post-16 education was interpreted as their only option in the context of severely limited employment opportunities, particularly for high-skilled jobs. 
Approximately a quarter of them made reference to such lack when explaining decisions to stay-on in $6^{\text {th }}$ form, which appeared to be less positive choice than necessity:

Res. So why did you decide to stay-on in $6^{\text {th }}$ form?

R. Because I didn't want to go to college cos it's too far away, and there's no real job opportunities really in the Rhondda Valley so there's no real option then really. (Robert, Rhondda)

Yeah well, yeah I think cos you know there's not so many jobs around for 16 year olds, like I tried for an apprenticeship and didn't get in so I had to stay-on. (Hywel, Rhondda).

While Hywel's positive prior experiences of education and level of previous academic attainment allowed his transition to post-16 education to be perfectly possible, he reported having decided to do so only after failing to obtain an apprenticeship. His assertion that 'I had to stay-on' suggests at least ambivalence, a second-bestness about doing so; local contexts had defined what he could objectively do, but did not necessarily match what he wanted to do. Similarly, Luke, Adam and Shaun illustrated the way in which staying on in post-16 education was constructed as the only possible option in the face of scarce labour market opportunities:

Res: Imagine that you hadn't stayed-on in $6^{\text {th }}$ form, what do you think you might be doing now if you hadn't stayed-on?

L. Probably applying for college I think cos that's...it's very hard for young people to get a job I think. I don't think I could have done anything else apart from go to college. (Luke, Rhondda)

Res: Why did you decide to stay-on in $6^{\text {th }}$ form?

A. Something to do (laughs)....na I wanna go to uni like, and there's nothing out there anyway is there if you leave school. (Adam, Rhondda)

S. Further my education I suppose, and university, I thought that would be a better way to go and there's not a lot of jobs about and things so I thought university would open doors and hopefully get something that way like. (Shaun, Rhondda)

These excerpts reveal the way in which young people's interpretations of their local opportunity structures inform the types of transitions they make from compulsory to post- 
compulsory education. Rhondda young people have in effect been 'pushed' into post-16 education by a scarcity of opportunity in local contexts, thus questioning the assumptions of human capital theory that people will only be incentivised to gain qualifications where they see the rewards for doing so. This is likely to be particularly so for young women for whom employment opportunities are particularly limited in the Rhondda. For young men, there are some, albeit severely limited, employment opportunities in trades such as building and plumbing (reflected in the large number of students' fathers holding these sorts of occupations). Thus, contrary to McDowell's (2003) finding that school leavers were more likely to stay in education in the context of successful labour markets the narratives presented here suggest that scarce rather than abundant opportunities in local contexts encourage people to stay in education, offering some support for a 'discouraged worker' hypothesis, of young people 'pushed' into post-16 education by the scarcity of local employment opportunities.

For students from Newport, by contrast, a different sort of process underpinned their transition to post-16 education. 'Staying on' was not so much constructed as the only option but, rather, the most valuable and rewarding alternative to entering a labour market with a substantial service-sector. In Newport nobody alluded to lack of employment opportunities when they qualified their decision to stay-on in post-16 education. Rather, it was frequently constructed as means of getting a 'better job':

Res: Why did you decide to stay-on in $6^{\text {th }}$ form?

N. I want to go further in education. Cos I think if you stay-on more in school and you work here you're gonna get a better job, I don't want to go straight into working, that's why. (Nathan, Newport)

P. So I could get better qualifications, so I could get a better job. (Paul, Newport)

Certainly, students from Newport, like those from the Rhondda, similarly constructed post-16 education and $\mathrm{HE}$ qualifications as both a means of gaining a competitive advantage within the labour market and a beneficial alternative to entering a congested labour market, as illustrated above and by Karimah's response below:

Res. So why do you think that it's important to go on to college?

K. Um, I'd say like it is important to go college because like you get to get a lot of qualifications like you get to learn quite a bit as well, but then at the same time I think it 
depends like I said before, like it depends what you want to be, so in a way it is important, because say, like these days it's hard to get a job as well so you rea...they look at the qualifications more. So I'd say in a way it is important these days. (Karimah, Newport)

Yet the overwhelming sense, expressed by young people from Newport that staying on in post-16 education is the most rewarding alternative to entering employment, set these young people apart from those from the Rhondda where post-16 education was more likely to be constructed as the only option. The proximity of Newport's young people to the city centre, a hub of employment opportunities within service-dominated industries, meant that they were more likely to perceive entering employment rather than $6^{\text {th }}$ form as a possibility, albeit one which they then rejected:

Res. Why did you decide to stay-on in $6^{\text {th }}$ form?

P. Um well I dunno I don't think that I wanted to get a full time job at 16, I think I wanted to go to uni cos, obviously for the uni experience and everything and get a good job at the end of it, pay off the debts and all of that so yeah I didn't want to go into full time employment, cos I got a part-time job now, so I don't think I could do that 5-6 days a week. (Pratik, Newport)

Pratik's experience of part-time employment and his reflection on the ease with which he secured it was clearly informed by his interpretation of the opportunity structures immediately surrounding him. His decision to stay in education was primarily informed by his aspiration toward HE and the opportunities it offered, both in terms of the 'uni experience' as well as getting a 'good job.' In his view, like that of others, HE was a valuable pathway yet he did not rule out the possibility of having a full time job now if he so chose.

\section{Discussion}

Young people's educational decisions are not simply informed by their social and economic circumstances, including educational, material and cultural resources (Ball et al. 2000). Historically specific landscapes of educational and economic opportunities also frame their decisions. In particular, contemporary discourses which postulate linear relationships between education and employment (Brown 2003), accentuated by contemporary economic events, bear heavily upon their transitions. In both research locations, young people's interpretations 
of the opportunities they faced were informed by their internalisation of culturally and historically situated discourses and as such, their educational decisions were powerfully framed by contemporary economic events.

The nature of these young people's educational decisions strongly suggest that both human capital theory and 'discouraged worked effect' are important in explaining young people's decisions to continue to post-16 education. However, neither is sufficient. For this reason, I turned to consider how local contexts frame decisions in order to gain greater understanding of the decision making process. This revealed differences between the young people living in either location in their 'articulated rationalities' for progressing on to post-16 education, reflecting different structures of employment opportunities present in these areas, and young people's interpretation of them. With very little replacement for employment in and around the mining industry, continuing in post-16 education had become the only option for young people from the Rhondda, particularly those academically successful. Entry to it constituted not so much a choice made between an equal set of alternatives, but within a severely limited set of options. Thus, young people were more likely to be 'pushed' into post-16 education by scarcity of local opportunity. In Newport, while labour market opportunities for the young were limited, they were not nearly as restricted as in the Rhondda Valleys. Staying on in post16 education was not so much the only, but the most rewarding option for securing labour market advantages in the context of recently slumped, now service sector dominated local industry. Thus, for its young people, transition to post-16 education was likely to be more of a positive choice; they were more likely to 'jump' into it in response to limited appropriate local employment opportunities.

Thus, in addressing the theoretical question outlined earlier regarding the extent to which educational decisions can be explained by cultural reproduction or rational choice explanations, it seems that a mixture of both is required in order to fully appreciate how localities frame educational decisions. Young people evidently make choices according to preference and intention, yet they do so within the boundaries of historically and spatially specific conditions which define the scope of objective opportunity structures (Rees et al. 1997). Since any objective set of opportunities is located within a particular historical time frame, and opportunities vary across place, the external forces that define the parameters within which people make their choices also vary over time and place. Educational and 
economic opportunities within national settings, as well as local opportunity structures and material resources and prior attainment, are the conditions that define the boundaries of what young people can objectively do. Echoing Gambetta's (1987) assertion that educational decisions are informed by both intentionality and causality, the young people in this study were making educational decisions informed by what they want to do, as well as what they can do (Gambetta 1987), that is, they were making educational decisions within parameters defined by external forces which are both social and spatial (Gambetta 1987).

Most importantly, this paper has illustrated that while locality did not seem to matter in terms of the immediate post-16 destinations of these young people, it did matter to the processes by which they reached this destination; they either 'jumped' or were 'pushed' in to it. We can see, therefore, that transitions are informed by rational and strategic decisions but not necessarily in the way that human capital theory conceptualises them. Participating in post-16 education seems to be as much about avoiding 'risky' transitions such as entering into labour markets characterised by severely restricted opportunities, as it is about investment in human capital. These findings suggest, therefore, that the nature of young people's post-school transitions and choices are informed by conditions in local contexts, but these cannot simply be understood as reflecting motives to invest in human capital, on the one hand, or a 'discouraged worker' effect on the other.

What might we speculate about the implications of these different types of transitions? Young people who are 'pushed' into educational pathways may have different experiences of postcompulsory education from those who 'jump'. Where young people are 'pushed', their transitions may be more tenuous, fragmented and convoluted and themselves, possibly, more vulnerable to drop out and non-completion in further or higher education than those who 'jump'. This in turn might make their pathways towards their hoped for destinations more fractured and fragmented. Drawing upon Rose's (1999: 104) assertion that work and career are the means through which we 'produce, discover and experience our selves' we might speculate that, in making tenuous transitions and being pushed down pathways which are not congruous with career aspirations, young people are unable to realise their aspirations to 'become' the 'self' to which they aspire. This possibly leaves them more vulnerable to 'drift' and to difficulties in realising career aspirations, weakening their chances of securing socially and financially rewarding jobs than those who appear to make more positive transitions and who 'jump'. These observations are necessarily speculative as to whether and how the type of 
transition young people make, whether they are 'pushed' or 'jump' into particular pathways, has bearing upon their future life chances. Further longitudinal research exploring the implications of these types of transitions would enable us to reveal the extent to which local opportunity structures really are implicated in the future life chances of young people.

If nothing more, this paper highlights the importance of transcending the use of 'locality' as a proxy measure for social class as an analytic lens through which to explore youth transitions. Based on the narratives of young people of this study we have seen that localities which share many traditional 'working-class' features have nuances in their historical, social and economic landscapes that are crucially important to young people's decisions about their post-school lives. Indeed, the paper's original contribution to youth transitions literature stems from its illumination of how nuanced local employment opportunities and young people's interpretation of them, inform the distinctive nature of the decision making process underpinning their transitions in a context of globally contracted employment opportunities in Wales. Of course, the scope of opportunities which young people face are informed by the material, social and cultural resources on which they can draw. Notwithstanding, young people who experience similar constraints and opportunities defined by economic and cultural resources may make very different sorts of educational decisions, critically depending on where they live.

\section{Notes}

1. The AS and A-level (Advanced subsidiary and Advanced level) are academic qualifications offered by educational settings in England, Wales and Northern Ireland, typically taken by 1619 year olds.

2. BTEC (Business and technology education council).

3. NVQ (National Vocational Qualification).

4. The Welsh Government promoted the expansion of vocational and academic courses to post16 learners in Wales through its 14-19 'Learning Pathways' initiative (Welsh Assembly 
Government 2004) which aimed to improve rates of attainment and progression to HE or high-skilled employment .

5. This paper draws on data collected as part of an ESRC funded PhD which explored how locality frames young people's educational decisions and transitions.

6. In the Rhondda Valleys in 2010 the percentage of the working age population (those aged 16 and over) who were unemployed exceeded the national average of 8.4 per cent at 11.6 per . In Newport, unemployment levels stood at roughly 10 per cent of the working age population (StatsWales, 2015)

7. The names of these schools have been changed in order to preserve their confidentiality.

8. The uneven numbers of young people from each location is partly attributed to the schools' timetabling constraints and pressures to ensure young people were not missing out on lessons running up to exam period.

9. Level 2 qualifications include General Certificate of Secondary Education (GCSE) grades A* C. Attainment of 5 GCSEs at A*-C contributes $100 \%$ to the level 2 'threshold.'

10. 'Communities First' is a Welsh Government community based programme for tackling poverty. Areas designated as 'Communities First' are those which fall within the top $10 \%$ most deprived according to measures on the Welsh Index of Multiple deprivation.

\section{Acknowledgments.}

This work was supported by funding from the economic and social research council (ESRC). I would like to thank the young people and their teachers who kindly gave up their time to be a part of this study and the anonymous reviews for their very helpful comments.

\section{References}

Ashton, D, Maguire, M and Spilsbury, M. 1990. Restructuring the labour market. The implications for youth. London: The Macmillan Press

Ball, S. J, Maguire, M and Macrae, S. 2000. Space, work and the 'new urban economies'. Journal of Youth Studies 3 (3), pp. 279-300 
Ball, S. J, Davies, J, David, M and Reay, D. 2002. 'Classification' and 'Judgment:' Social class and the 'cognitive structure' of choice of higher education. British Journal of Sociology of Education 23 (1), pp. 51-72

Bates, I and Riseborough, G. 1993. Youth and Inequality. Buckingham: Open University Press.

Biggart, A and Furlong. A. 1996. Educating 'Discouraged workers': Cultural diversity in the upper secondary school. British Journal of Sociology of Education. 17 (3), pp. 253-266

Boudon, R. 1974. Education, Opportunity and Social Inequality. New York: Wiley.

Bourdieu, P. 1977. Reproduction in Education, Society and Culture. London: Sage.

Brown, P. 2003. The opportunity Trap: education and employment in a global economy. European Educational Research Journal. 2. (1), pp. 141-179

CareersWales. 2015. Pupil destinations from schools in Wales 2013. [Online]Available at: http://destinations.careerswales.com/year11.htmll [Accessed:16.02.15]

Coffield, F, Borrill, C and Marshall, S. 1986. Growing up on the Margins. Milton Keynes: Open University Press.

Dolton, P and Vignoles, A. 2000. The incidence and effects of overeducation in the UK graduate labour market. Economics and Education Review. 19, pp. 179-198

Furlong, A and Cartmel, F. 1995. Aspirations and opportunity structures: 13-year-olds in areas with restricted opportunities. British Journal of Guidance and Counselling. 23(3) pp $361-375$

Furlong, A and Kelly, P. 2005, The Brazilianisation of youth transitions in Australia and the UK? Australian Journal of Social Issues, vol. 40, no. 2, pp. 207-225.

Gambetta, D. 1987. Were they pushed or did they jump? Individual decision mechanisms in education. London: Cambridge University Press.

Garner, C, Main, B.G.M and Raffe, D. 1988. A Tale of Four Cities: Social and Spatial Inequalities in the Youth Labour Market. In: David Raffe (Ed). Education and the Youth Labour Markets. London: The Falmer Press. Pp, 132-147 
Glaesser, J and Cooper, B. 2013. Using Rational Action Theory and Bourdieu's habitus theory together to account for educational decision making in England and Germany. Sociology. 0 (0), pp. 1-19.

Goldthorpe, J. H. 1996. Class analysis and the reorientation of class theory: The case of persisting differential in educational attainment. The British Journal of Sociology. 47 (3), pp 481-505

Gorard, S and Rees, G. 2002. Creating a Learning Society? Bristol: Policy Press

MacDonald, R, Shildrick, T, Webster, C and Simpson, D. 2005. Growing up in poor neighbourhoods: The significance of class and place in the extended transitions of 'socially excluded' young adults. Sociology. 39 (5), pp. 873-891

Mayhew and Keep, 2004. The economic and distributional implications of current policies on higher education. Oxford Review of Economic Policy 20 (2), pp 298-314

McDowell, L. 2003. Redundant Masculinities? Employment changes and white working class youth. Oxford: Blackwell

McLeod, J and Yates, L. 2006. Making Modern Lives. Subjectivity, Schooling and Social Change. Albany: State University of New York Press

Parker, A. 2000. Rational choice or 'Hobson's choice'? Intention and constrain in UK higher education. In Archer, M.S and Tritter, J.Q. Eds. Rational Choice Theory. Resisting Colonisation. London: Routledge. Pp, 126-143

Pring, R, Hayward, G, Hodgson, A, Johnson, J, Keep, E, Oancea, A, Rees, G, Spours, K and Wilde, S. 2009. Education for All. The Future of Education and Training for 14-19 year olds. London: Routledge.

Raffe, D and Willms, J. D. 1989. Schooling and the discouraged worker: Local labour market effects on educational participation. Sociology. 23 (4), pp. 559-581

Rees, G, Fevre, R, Furlong, J and Gorard, S. 1997. History, place and the learning society: towards a sociology of lifetime learning. Journal of Education Policy. 12, (6), pp. 485-497

Reay, D. Davies, J, David, M and Ball, S.J. 2001. 'Choice of degree of degrees of choice? Class, 'race' and the higher education choice process. Sociology. 35 (4), pp. 855-874 
Roberts, K. 1984. School leavers' and their Prospects. Young Labour markets in the 1980s. Milton Keynes: Open University Press.

Roberts, K. 1995. Youth and employment in modern Britain. Oxford: Oxford University Press.

Rose, N. 1999. Governing the Soul. The Shaping of the Private Self. London: Free Association Books

Shah, A. 2010. 'Global financial crisis' [Online] Available at: http://www.klettsprachen.de/download/3612/Viewfinder-Global-Village-Global-financial-crisis.pdf [Accessed $16 / 02 / 15]$.

StatsWales. 2015. ILO Unemployment rates by Welsh local areas and year. [Online] Available at: https://statswales.wales.gov.uk/Catalogue/Business-Economy-and-LabourMarket/People-and-Work/Unemployment/ILO-Unemployment/ILOUnemploymentRates-byWelshLocalAreas-Year [Accessed 16.02.15]

Welsh Assembly Government, 2004. Learning Pathways 14-19 Guidance. Department for training and education. 